\title{
Endoscopic Lumbar Discectomy Using Side-Viewing Conical Working Tube: An Institutional Experience
}

\author{
Mohammad Kaif ${ }^{1}$ Kuldeep Yadav ${ }^{1}$ 이 Khursheed Alam Khan ${ }^{1}$ Rakesh Kumar ${ }^{1}$ \\ Deepak Kumar Singh ${ }^{1}$ Faran Ahmad ${ }^{1}$ \\ ${ }^{1}$ Department of Neurosurgery, Dr Ram Manohar Lohia Institute of \\ Medical Sciences, Lucknow, Uttar Pradesh, India \\ Indian J Neurosurg 2023;12:37-41. \\ Address for correspondence Mohammad Kaif, MCh, Department of \\ Neurosurgery, Dr Ram Manohar Lohia Institute of Medical sciences, \\ Lucknow 226010, Uttar Pradesh, India \\ (e-mail: dr_kaifmohd@yahoo.co.in).
}

\begin{abstract}
Keywords

- lumbar disc herniation

- endoscopic discectomy

- side-viewing channel

Objective The paradigm of surgical therapy for spinal disease especially for lumbar disc herniation (LDH) has gradually shifted from the traditional open surgeries to minimal invasive spinal surgeries. Endoscopic discectomy has been performed widely using various devices and techniques. In this study we present our experience of endoscopic discectomy using a unique device with separate side-viewing channel.

Methods Twenty-six patients with LDH treated between March 2015 and April 2018 using the unique conical working tube with separate side-viewing endoscopic channel have been retrospectively analyzed. Their preoperative and postoperative Oswestry Disability Index (ODI) and Macnab scores were used to evaluate the outcome with a mean follow-up of 37.04 months.

Results There were 18 males and 8 females with age ranging from 19 to 72 years (mean, 38.4 years). The follow-up ranged from 25 to 60 months with mean of 37.04 months. The mean preoperative ODI score was 72.4 , which decreased to a mean of 7.6 and the outcome evaluated by Macnab criteria was $65.3 \%$ excellent, $19.2 \%$ good, $11.5 \%$ fair, and $3.8 \%$ poor. One patient underwent second surgery. None of the patients had to change their occupation postoperatively. Complications that occurred were dural tear in one patient and transient foot paresis in one, which improved spontaneously.

Conclusion Endoscopic discectomy using conical working tube is a safe and effective technique for lumbar disc prolapse. The long-term results are comparable to the conventional techniques.
\end{abstract}

\section{Introduction}

Endoscopic lumbar discectomy for lumbar disc herniation (LDH) has been an ever-evolving procedure since its inception, because of the benefits it caters over open surgery. Open surgical procedures for LDH are associated with greater muscle, nerve roots and dural sac retraction, lamina and facet joint resection, etc. This leads to more muscular injury, epidural scarring, postoperative pain, longer hospital stays, and greater blood loss.

Endoscopic lumbar discectomy overcomes these associated drawbacks of open surgery for LDH but is associated with its own difficulties and complications. Steep learning curve, endoscopic approach related anatomical limitations, and vague tissue differences are few problems associated with endoscopic procedures. Various devices have been developed article published online May 25, 2021
DOI https://doi.org/ $10.1055 / \mathrm{s}-0041-1727417$. ISSN 2277-954X.

\footnotetext{
(c) 2021. Neurological Surgeons' Society of India. All rights reserved. This is an open access article published by Thieme under the terms of the Creative Commons Attribution-NonDerivative-NonCommercial-License, permitting copying and reproduction so long as the original work is given appropriate credit. Contents may not be used for commercial purposes, or adapted, remixed, transformed or built upon. (https://creativecommons.org/ licenses/by-nc-nd/4.0/)

Thieme Medical and Scientific Publishers Pvt. Ltd., A-12, 2nd Floor, Sector 2, Noida-201301 UP, India
} 
to increase the ease of procedure and reduce the learning curve along with associated complications. Kambin and Gellman first introduced endoscopic lumbar discectomy in 1973. ${ }^{1}$ Later various devices were introduced like Yeung endoscopic spine system, transforaminal endoscopic spine system, Destandau system. ${ }^{2-4}$ Similarly, various authors have reported their experience of endoscopic discectomy using different devices, although many of these lack the literature on long-term results of endoscopic surgery. ${ }^{4-7}$ In this article we present our institutional experience of endoscopic discectomy using the conical working tube with separate viewing channel.

\section{Methods}

\section{Study Setting}

This study was conducted in the Department of Neurosurgery, Dr Ram Manohar Lohia Institute of Medical Sciences, Lucknow, India.

\section{Study Design and Period}

It is a retrospective study based on follow-up of 26 patients with LDH treated using the conical working tube with sideviewing endoscopic channel. ${ }^{8}$ The hospital records of 38 patients who underwent endoscopic lumbar discectomy using this device between March 2015 and April 2018 were retrieved. Only those patients were included in this study who could be contacted on telephone and responded to the Oswestry Disability Index (ODI) and Macnab score formats.

\section{Study Participants}

Endoscopic surgery was conducted on patients who presented with low backache along with radicular pain in lower limbs with or without neurological deficit and failed conservative management. Patients with segmental instability, no clinico-radiological correlation, or evidence of infection were excluded from this study. There were 18 males and 8 females with age ranging from 19 to 72 years (mean, 38.4 years). The follow-up ranged from 25 to 60 months with mean of 37.04 months.

\section{Instrument Design}

This device comprises of a conical working tube that is passed over coaxial dilators and secured in position by a holding device attached to the operating table. It has a separate sideviewing channel for the telescope, which is attached to a light source and camera. No special instruments are used for laminotomy and discectomy (-Fig. 1).

\section{Operative Technique}

Patient is positioned prone after general anesthesia on a Wilson's frame or foam bolsters. Level is localized using fluoroscopy. Incision deep to fascia is given $1 \mathrm{~cm}$ lateral to midline. First, a dilator is passed with a $5 \mathrm{~mm}$ trocar up to the lamina and the trocar is removed. Gentle medial to lateral and cranial to caudal sweeping movements are done for the elevation of soft tissue. Serial dilators are passed over this first tube followed by the working tube over these dilators, which is finally fixed to table after removal of serial dilators. Position of the working tube is confirmed under fluoroscopy. A cannula with trocar is passed from the separate side channel through a separate stab incision and locked in the working tube using the locking mechanism. A zero-degree telescope (4 mm diameter and $180 \mathrm{~mm}$ length) is passed through this separate channel. The tip of the telescope just reaches up to the inner part of the working tube. The light source and camera are attached to the cannula and the image orientation is done by rotating the camera on scope (-Fig. 1).

Medial part of the facet and contiguous lamina are identified. A small hemi-laminotomy and medial facetectomy were done using Kerrison rongeur. The ligamentum flavum is detached from the under surface of the lamina and removed. Traversing nerve root and thecal sac are identified using a ball probe.

The nerve root is retracted medially and the disc is removed by entering the disc space through the annular tear or an annulotomy. The disc space is irrigated with normal saline to wash out the loose disc fragments. The nerve root is inspected to ensure adequate decompression (-Fig. 2). The entire assembly is removed and the fascia is closed with absorbable suture. Skin is closed using subcuticular sutures.
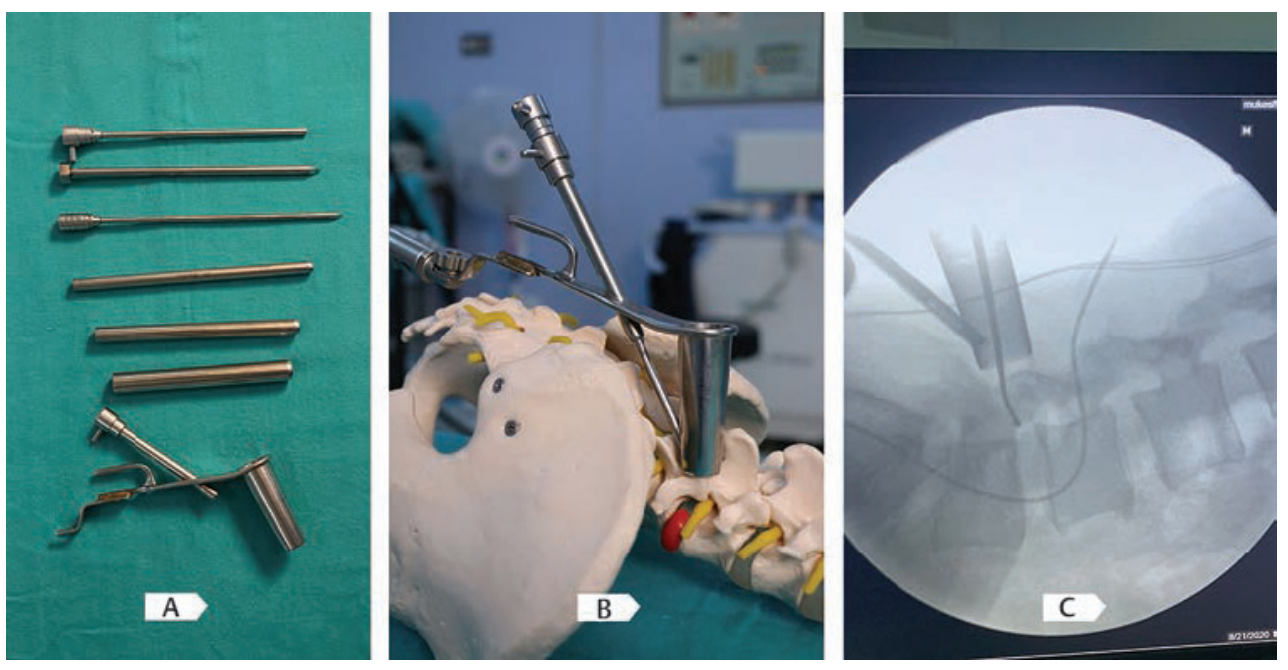

Fig. 1 (A) Instrument design, (B) instrument setup with telescope and light source, and (C) fluoroscopic view with endoscopic device. 

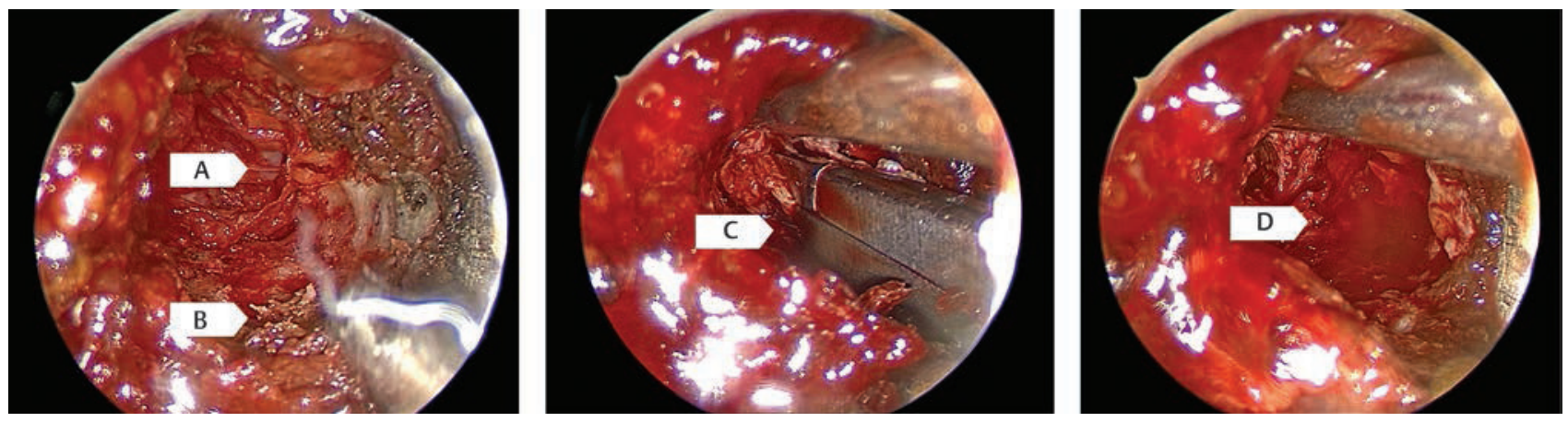

Fig. 2 (A) Nerve root, (B) medial part of facet joint, (C) disc fragment being excised, and (D) disc space after discectomy.

\section{Postoperative Management}

Patients were mobilized in the evening of the day of surgery and were discharged on the next postoperative day. In this study the mean hospital stay was 1.6 days.

\section{Complications}

An incidental dural tear was observed in one patient. This was managed by sealing the defect by fibrin glue. No postoperative cerebrospinal fluid leak or pseudomeningocele or any longterm sequelae was observed. The other postoperative complication was transient foot paresis in one patient, which improved spontaneously.

\section{Results}

Patients were evaluated using ODI score. The score was interpreted as 0 to $20 \%$ (minimal disability), 21 to $40 \%$ (moderate disability), 41 to 60\% (severe disability), 61 to $80 \%$ (crippled), and 81 to $100 \%$ (bed bound/exaggerating their symptoms). Both the preoperative and postoperative ODI were compared and its differences were calculated. The mean preoperative ODI score was 72.4, which decreased to a mean of 7.6 postoperatively. The final outcome was evaluated using Macnab criteria, which was divided into excellent, good, fair, and poor categories. As per Macnab criteria, $65.3 \%(n=17)$ had excellent outcome, $19.2 \%(n=05)$ had good, $11.5 \%(n=03)$ had fair, and 3.8\% $(n=01)$ had poor outcome. One patient experienced persistent radicular pain of same intensity and was diagnosed to have a residual disc fragment, which was removed later by microsurgery. None of the patients had to change their occupation due to their lumbar disc disease (-Table $\mathbf{1}$ ).

\section{Discussion}

Lumbar intervertebral disc herniation, leading to various symptoms, has been catered through multiple operative modalities. The classic discectomy described by Mixter and Barr ${ }^{9}$ has undergone a series of modifications to develop into the present-day discectomy procedure. ${ }^{10}$ The classic discectomy required a larger incision, separation and retraction of paraspinal muscles that led to an increase in postoperative morbidity such as increased pain, a delay in resuming activities, and a lengthy hospital stay with
Table 1 Summary of procedure-related data

\begin{tabular}{|l|l|l|}
\hline Sr. no & Procedural characteristics & Value \\
\hline 1 & Outcome & \\
\cline { 2 - 3 } & Macnab & $n=17(65.3 \%)$ \\
\cline { 2 - 3 } & Excellent & $n=5(19.2 \%)$ \\
\cline { 2 - 3 } & Good & $n=3(11.5 \%)$ \\
\cline { 2 - 3 } & Fair & $n=1(3.8 \%)$ \\
\cline { 2 - 3 } & Poor & 72.4 \\
\cline { 2 - 3 } & Oswestry Disability Index (ODI) \\
\cline { 2 - 3 } & Mean preoperative score & \\
\cline { 2 - 3 } & Mean postoperative score & 7.6 \\
\hline 2 & Complications & $n=1(3.8 \%)$ \\
\cline { 2 - 3 } & Dural tear & $n=1(3.8 \%)$ \\
\cline { 2 - 3 } & Transient foot paresis & (3.8\%) \\
\hline 3 & Repeated surgery & \\
\hline
\end{tabular}

significant financial burden on patients especially in a developing nation. Moreover, the extensive surgery could lead to the instability of spine with due course of time.

To overcome the disadvantages and problems associated with classic discectomy, various minimal invasive techniques have been developed. In 1978, Williams ${ }^{11}$ described micro discectomy that established as a guide to a lesser invasive approach to lumbar spine. This was the mini variant of conventional discectomy through a much smaller incision as compared with the previous technique. Howe and Frymoyer ${ }^{12}$ reported a success rate of 60 to $97 \%$ with the micro discectomy but it still required the separation of paraspinal muscles from the lamina and spinous process leading to the denervation of the paraspinal muscle complex and causing a delay for the patient in resuming daily activities.

Endoscopic spinal surgery began as percutaneous endoscopic discectomy. Kambin (1973) and Hijikata et al (1975) had attempted the earliest endoscopic surgery in the 1970s. ${ }^{13,14}$ Since then this technique has got modifications through generations, ${ }^{14}$ to improve the patient outcome and increase the domain of indications for endoscopic spine surgery (- Table 2). ${ }^{16-25}$ Various authors have described their results of micro endoscopic discectomy (MED), some 
Table 2 Generations of endoscopic spinal surgery

\begin{tabular}{|l|l|l|l|}
\hline First generation & Second generation & Third generation & Newer innovation \\
\hline Yeung endoscopic spine system & $\begin{array}{l}\text { Interlaminar uniportal } \\
\text { endoscopic spine surgery }\end{array}$ & Endoscopic decompression & $\begin{array}{l}\text { Endoscopic lumbar interbody } \\
\text { fusion surgery }\end{array}$ \\
\hline $\begin{array}{l}\text { Percutaneous endoscopic } \\
\text { lumbar discectomy }\end{array}$ & $\begin{array}{l}\text { Interlaminar biportal } \\
\text { endoscopic spine surgery }\end{array}$ & Endoscopic foraminotomy & \\
\hline $\begin{array}{l}\text { Transforaminal endoscopic } \\
\text { lumbar discectomy }\end{array}$ & & & \\
\hline
\end{tabular}

Table 3 Studies of endoscopic discectomy

\begin{tabular}{|c|c|c|c|c|c|}
\hline Author/year & $\begin{array}{l}\text { Number } \\
\text { of } \\
\text { patients }\end{array}$ & $\begin{array}{l}\text { Outcome } \\
\text { measures }\end{array}$ & Outcome & Recurrence & Complication \\
\hline Kulkarni et al, $2014^{16}$ & 188 & VAS, ODI & $\begin{array}{l}\text { Statistically } \\
\text { significant pain relief }\end{array}$ & $3(1.5 \%)$ & $\begin{array}{l}11(5 \%) \text { dural } \\
\text { tears, } 1(0.5 \%) \\
\text { infection, } 1(0.5 \%) \\
\text { wrong level }\end{array}$ \\
\hline Hussein et al, $2014^{17}$ & 185 & $\begin{array}{l}\text { NRS, Macnab, } \\
\text { ODI }\end{array}$ & $\begin{array}{l}\text { Statistically } \\
\text { significant pain relief }\end{array}$ & $\begin{array}{l}2 \text { converted } \\
\text { to open }\end{array}$ & 3 dural tears \\
\hline Li et al, $2015^{18}$ & 72 & $\begin{array}{l}\text { VAS, ODI, } \\
\text { Macnab }\end{array}$ & $97 \%$ good to excellent & 1 & No complications \\
\hline Kyung Chul Choi et al, $2016^{19}$ & 20 & VAS, ODI & $91.3 \%$ good to excellent & 1 & $\begin{array}{l}1 \text { transient } \\
\text { neurological deficit }\end{array}$ \\
\hline Sung Soo Eun et al, $2016^{20}$ & 62 & VAS, Macnab & Significant pain relief & 6 & 2 dural tears \\
\hline Kyung Chul Choi et al, $2017^{21}$ & 149 & VAS, ODI & $90.6 \%$ good improvement & 4 & $\begin{array}{l}1 \text { transient } \\
\text { neurological deficit }\end{array}$ \\
\hline Kaif et al, $2017^{22}$ & 66 & $\begin{array}{l}\text { VAS, ODI, } \\
\text { Macnab }\end{array}$ & $86.36 \%$ good to excellent & 2 & $\begin{array}{l}\text { Discitis } 1 \text {, dural } \\
\text { tear } 2 \text {, transient } \\
\text { foot paresis } 1\end{array}$ \\
\hline Hyung Sun Kim et al, $2018^{23}$ & 98 & VAS, ODI & $96.1 \%$ good to excellent & 3 & $\begin{array}{l}2 \text { neurological } \\
\text { deficits }\end{array}$ \\
\hline Ziquan Li et al, $2019^{25}$ & 21 & VAS, ODI & Significant improvement & 0 & $\begin{array}{l}2 \text { dural tears, } \\
1 \text { dysesthesia }\end{array}$ \\
\hline Chao Li et al, $2019^{24}$ & 184 & $\begin{array}{l}\text { VAS, ODI, } \\
\text { Macnab }\end{array}$ & $89.3 \%$ good to excellent & 14 & $\begin{array}{l}4 \text { dural tears, } \\
1 \text { neurological deficit }\end{array}$ \\
\hline
\end{tabular}

Abbreviations: NRS, Numerical Rating Scale; ODI, Oswestry Disability Index; VAS, Visual Analogue Scale.

of which are mentioned in - Table 3. Jensdottir et al in their retrospective study reported a good/excellent outcome of micro discectomy. ${ }^{26}$ Casal-Moro et al in their prospective study reported that MED is a safe technique with lesser tissue trauma and comparable results to that of conventional techniques. $^{27}$ Bhaisare et al reported their experience using the Destandau technique with excellent short- and long-term results. ${ }^{28}$

Our study also reveals similar results regarding the excellent/good outcome of the patients using our specific side-viewing conical working tube. The results with this device were excellent to good in $84.5 \%$ of cases after a mean follow-up of 37.04 months, which is comparable with other studies of all the minimally invasive lumbar discectomy techniques practiced worldwide. Casalmoro reported surgical complication rate of 3 to $10 \%$ in various techniques whereas Destandau in his series reported 3.5\%, and four of his patients required reoperation. ${ }^{22}$ In our series we experienced $7.7 \%(n=2)$ of such complications and $3.8 \%$ $(n=1)$ required reoperation.

The popular device used for MED is the METRx system, which is a serial dilator system utilizing the interlaminar corridor. It has a telescope mounted at the top end edge of the working channel, but as experienced by the senior surgeons this technique causes clutter while working bimanually through the working tube. The other disadvantage is the high cost of the specialized hardware. The Destandau system is another popular device with excellent to good long-term results but it has the disadvantage that direct visualization using naked eye or microscope is not possible and also minimally invasive interbody fusion cannot be performed through this device. The costs of these devices are very high, 
which is one of the major hindrances in expansion of this technique. Our system is an indigenous innovation with a very low cost. The freedom of surgical maneuverability is the advantage. $^{8}$ The hardware cost is further reduced as it utilizes the conventional discectomy instruments and same telescope that is used in transcranial endoscopic surgeries.

\section{Conclusions}

Endoscopic discectomy using this conical working tube is a safe, effective, and low-cost technique for lumbar disc prolapse. It has the advantage for early mobilization, short hospital stays, and lower financial burden. Overall outcome is comparable to the conventional techniques.

\section{Limitation}

Our study has limitations with the retrospective nature of the data collection. Small sample size is also a limitation of this study.

\section{Conflict of Interest}

None declared.

\section{References}

1 Li X, Hu Z, Cui J, et al. Percutaneous endoscopic lumbar discectomy for recurrent lumbar disc herniation. Int J Surg 2016;27:8-16

2 Yeung AT, Tsou PM. Posterolateral endoscopic excision for lumbar disc herniation: surgical technique, outcome, and complications in 307 consecutive cases. Spine 2002;27(07):722-731

3 Hoogland T, Schubert M, Miklitz B, Ramirez A. Transforaminal posterolateral endoscopic discectomy with or without the combination of a low-dose chymopapain: a prospective randomized study in 280 consecutive cases. Spine 2006;31(24): E890-E897

4 Destandau J. [Technical features of endoscopic surgery for lumbar disc herniation: 191 patients]. Neurochirurgie 2004;50(01):6-10

5 Destandau J. A special device for endoscopic surgery of lumbar disc herniation. Neurol Res 1999;21(01):39-42

6 Lysoń T, Mariak Z, Jadeszko M, Kochanowicz J, Lewko J. Results of Destandau microendoscopic lumbar discectomy. Neurol Neurochir Pol 2008;42(02):105-111

7 Bhandari S. Early experiences in endoscopic lumbar discectomy by Destandau technique for prolapse intervertebral disc. J Maharashtra Orthop Assoc. 2006;4:174-179

8 Husain M, Jha DK, Agrawal S, Husain N, Gupta RK. Conical working tube: a special device for endoscopic surgery of herniated lumbar discs. J Neurosurg Spine 2005;2(03):265-270

9 Mixter WJ, Barr JS. Rupture of the intervertebral disc with involvement of the spinal canal. $N$ Engl J Med 1934; 211:210-215

10 Smith MM, Foley KT. Microendoscopic discectomy (MED): surgical technique and initial clinical results. Proceedings of the Thirteen Annual Meeting of the joint section of Disorders of the Spine and Peripheral Nerve of the American Association of Neurological Surgeons; 1997 Feb; Newport Beach, CA
11 Williams RW. Microlumbar discectomy: a conservative surgical approach to the virgin herniated lumbar disc. Spine 1978;3(02): $175-182$

12 Howe J, Frymoyer JW. The effects of questionnaire design on the determination of end results in lumbar spinal surgery. Spine 1985;10(09):804-805

13 Kambin P, Brager MD. Percutaneus posterolateral discectomy. Anatomy and mechanism. Clin Orthop Relat Res 1987;223:145-154

14 Hijikata S, Yamagishi M, Nakayama T, Oomori K. Percutaneous nucleotomy: a new treatment method for lumbar disc herniation. J Toden Hop 1975;5:5-13

$15 \mathrm{Kim}$ M, Kim H-S, Oh SW, et al. Evolution of spinal endoscopic surgery. Neurospine 2019;16(01):6-14

16 Kulkarni AG, Dhruv A, Bassi A. Microendoscopic lumbar discectomy : Technique and results of 188 cases. Indian J Orthop 2014;48(01):81-87

17 Hussein M, Abdeldayem A, Mattar MM. Surgical technique and effectiveness of microendoscopic discectomy for large uncontained lumbar disc herniations: a prospective, randomized, controlled study with 8 years of follow-up. Eur Spine J 2014;23:1992-1999

18 Li Z.-Z., Hou S.-X., Shang W.-L., Song K.-R., Zhao H.-L. “The strategy and early clinical outcome of full-endoscopic L5/S1 discectomy through interlaminar approach,". Clinical Neurology and Neurosurgery 2015;133:40-45

19 Choi KC, Kim JS, Park CK. Percutaneous Endoscopic Lumbar Discectomy as an Alternative to Open Lumbar Microdiscectomy for Large Lumbar Disc Herniation. Pain Physician19(02): E291-E300

20 Eun SS, Lee SH, Sabal LA. Long-term Follow-up Results of Percutaneous Endoscopic Lumbar Discectomy. Pain Physician 2016 Nov-Dec;19(08):E1161-E1166

21 Choi KC, Lee DC, Shim HK, Shin SH, Park CK. A Strategy of Percutaneous Endoscopic Lumbar Discectomy for Migrated Disc Herniation. World Neurosurgery99:259-266

22 Kaif M, Yadav K, Husain M. Long term results of Endoscopic Lumbar Discectomy using Side viewing Conical working tube. Romanian Neurosurgery 2018;XXXII(02):306-313

23 Kim HS, Paudel B, Jang JS, Lee K, Oh SH, Jang IT. Percutaneous Endoscopic Lumbar Discectomy for All Types of Lumbar Disc Herniations (LDH) Including Severely Difficult and Extremely Difficult LDH Cases. Pain Physician 2018;21(04):E401-E408

24 Liu C, Zhou Y. Percutaneous endoscopic lumbar discectomy and minimally invasive transforaminal lumbar interbody fusion for massive lumbar disc herniation. Clin Neurol Neurosurg 2019; 176:19-24

25 Li Z, Zhang C, Chen W, et al. Percutaneous Endoscopic Transforaminal Discectomy versus Conventional Open Lumbar Discectomy for Upper Lumbar Disc Herniation: A Comparative Cohort Study. Biomed Res Int 2020;2020:1852070

26 Jensdottir M, Gudmundsson K, Hannesson B, Gudmundsson G. 20 years follow-up after the first microsurgical lumbar discectomies in Iceland. Acta Neurochir (Wien) 2007;149(01):51-58, discussion 57-58(wein)

27 Casal-Moro R, Castro-Menéndez M, Hernández-Blanco M, Bravo-Ricoy JA, Jorge-Barreiro FJ. Long-term outcome after microendoscopic diskectomy for lumbar disk herniation: a prospective clinical study with a 5-year follow-up. Neurosurgery 2011;68(06):1568-1575, discussion 1575

28 Bhaisare R, Kamble B, Patond K. Long-term results of endoscopic lumbar discectomy by "Destandau's technique". Asian Spine J 2016;10(02):289-297 